\title{
DETECTION OF EXTENDED-SPECTRUM $\beta$-LACTAMASE ENZYMES (ESBLS) PRODUCED BY ESCHERICHIA COLI URINARY PATHOGENS AT ASSIUT UNIVERSITY HOSPITAL
}

\author{
Amany G. Thabit ${ }^{1}$, Tharwat R. El-Khamissy ${ }^{2}$, Maggie A. Ibrahim ${ }^{1}$ and Adel E. Attia ${ }^{2}$ \\ ${ }^{1}$ Department of Microbiology and Immunology, Faculty of Medicine, Assiut University \\ ${ }^{2}$ Department of Microbiology, Faculty of Pharmacy, Al-Azhar University, Assiut

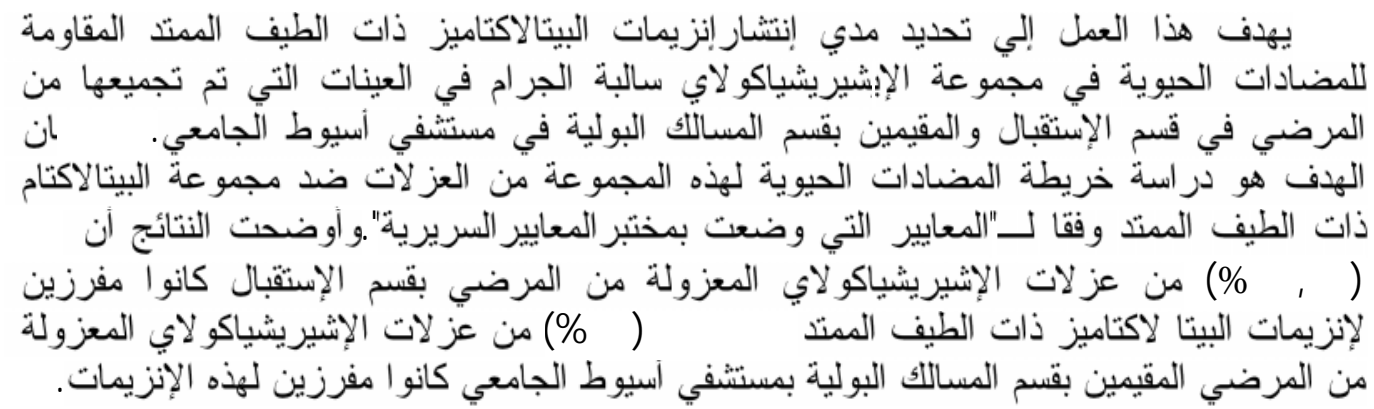

This study was conducted to evaluate the rate of urinary tract infection at Assiut University Hospitals, and to determine the prevalence of extended-spectrum $\beta$-lactamase enzymes producing community- and hospital-acquired E. coli uropathogens at Urology Department in Assiut University Hospitals. Also, to perform the antimicrobial sensitivity testing for E. coli isolates to extended-spectrum cephalosporins according to CLSI. Phenotypic confirmatory tests (combined disc method, double disc diffusion method and ESBL-E-Test) were performed to test E. coli isolates for ESBL production and it was concluded that $30(39.47 \%)$ of community isolates and 42 (70\%) of nosocomial isolates were ESBLs producers.

\section{INTRODUCTION}

Urinary tract infections (UTIs) are one of the most common infections encountered in the population. They are usually classified according to the anatomical part of the urinary tract affected; kidneys (acute pyelonephritis), bladder (cystitis), urethra (urethritis). It can be either community acquired or hospital acquired $^{1}$. UTI is the second most common type of infection in the human body. There are 150 million urinary tract infections estimated per year worldwide ${ }^{2}$. UTI is a bacterial infection that affects any part of the urinary tract. In most cases bacteria travel to the urethra and multiply causing kidney infection if not treated ${ }^{3 \& 4}$. E. coli is the most common cause of UTI among virtually every patient group and accounts for 80 to $90 \%$ of cases of uncomplicated pyelonephritis and cystitis ${ }^{5}$.

Extended-spectrum $\beta$-lactamases (ESBLs) producing Gram-negative bacteria are large, rapidly evolving group of plasmid-mediated enzymes emerging pathogens. Clinicians, microbiologists, infection control practitioners and hospital epidemiologists are concerned about ESBL-producing bacteria because of the increasing incidence of such infections. This is because of limitations of effective antimicrobial drug therapy and adverse patient outcomes. Some studies have shown high prevalence of ESBLs among various Enterobacteriaceae in hospitals in developing countries. However, little information is available regarding prevalence within the community $^{6 \& 7}$.

ESBLs are enzymes that mediate resistance to third generation oxyimino cephalosporins (e.g., ceftazidime, cefotaxime and ceftriaxone) and monobactams (e.g., aztreonam) but do not affect cephamycins (e.g., cefoxitin and cefotetan) or carbapenems (e.g., meropenem or imipenem). They are inhibited by either clavulanate (CA) or sulbactam, or tazobactam. ESBL production is originally observed in E. coli and Klebsiella spp., and has 
now been documented in other Gram-negative bacilli, including Enterobacter spp., Proteus mirabilis and Providencia stuartii ${ }^{8-10}$.

Widespread use of antibiotics without properly identifying the organism or its antibiotic sensitivity pattern has led to recurrent urinary tract infections or the emergence of multi-drug resistant organisms ${ }^{11}$. ESBL can be present in patients in the hospital and residents in personnel care homes. These bacteria can be spread through hands, especially after using the bathroom. The spread of ESBL in a hospital can occur most commonly, through contact with another person that has an ESBL, or on the hands of health care workers ${ }^{12}$. Rates of colonization by ESBL-producing organisms have increased dramatically worldwide ${ }^{13}$. This change has been associated with efficient dispersion of specific clones and plasmids harboring bla genes ${ }^{14}$. A threatening epidemiological problem is the dissemination of ESBL-producing organisms to healthy people in the community, which might depend on the frequency of ESBL fecal carriage as well as on the presence of ESBL-producing organisms in the food chain ${ }^{15}$.

The Clinical and Laboratory Standards Institute (CLSI) recommends the screening for ESBL and confirmation for isolates of $E$. coli and Klebsiella spp. ${ }^{16}$ Many laboratories have difficulty in detecting ESBL- or AmpCmediated resistance and may be unaware of the relevant CLSI reporting guidelines ${ }^{17}$. CLSI recommends performing phenotypic confirmation of potential ESBL- producing isolates of $K$. pneumoniae, $K$. oxytoca, or $E$. coli by testing both cefotaxime and ceftazidime, alone and in combination with clavulanic acid. Testing can be performed either by the broth micro-dilution method or by the disc diffusion method ${ }^{18}$.

\section{Aim of the work}

This study was conducted to determine the prevalence of ESBLs multidrug resistant isolates of $E$. coli isolated from patients presented to Urology Department at Assiut University Hospital. In addition to, studying the antibiogram profiles of them according to the CLSI. Also, many phenotypic and genotypic methods are used in ESBL estimation.

\section{PATIENTS AND METHODS}

\section{Patients}

This prospective cohort study was conducted on patients presented to the urology department at Assiut university hospital, Egypt. During the period from January 2009 to June 2009, a total of 700 patients were enrolled in this work. Hospital-onset infection was indicated by positive results of culture of specimens collected > 2 days after hospital admission, and community-onset infection was indicated by positive results of culture of specimens collected $\leq 2$ days after hospital attending.

\section{Sample collection}

Fresh mid-stream urine samples were collected. Catheter collection was restricted to those patients who were unable to produce mid-stream urine sample.

\section{Sample processing}

Immediate processing of the samples after collection was done to avoid samples contamination. Samples which couldn't be transported to the laboratory quickly were refrigerated at $4{ }^{\circ} \mathrm{C}$ for only several hours.

\section{Macroscopical examination of urine samples}

Physical examination of fresh uncentrifuged urine was performed for presence of turbidity. The five most common causes of turbidity are leukocytes, erythrocytes, epithelial cells, bacteria and amorphous materials ${ }^{19}$.

Viable bacterial count was performed for urine samples using the pour plate method ${ }^{20}$. The presence of 100,000 or more bacteria (CFU) per $\mathrm{ml}$ is considered as a positive culture (significant bacteriuria), where as lower numbers of organisms is considered as a negative culture, being mainly contaminants which have entered the urine from urethra or external genitalia while the specimen was being voided.

\section{Microscopical examination of urine samples}

Microscopic examination of centrifuged urine was performed for pus cell (WBC) count by high power field (HPF) (Pyuria means $\geq 5$ pus cells/HPF) ${ }^{21}$. 
The urine samples were centrifuged; cultures were done from the deposit on the following culture media (Oxoid, UK): Blood agars, chocolate agar, CLED agar, MacConkey's agar and EMB agar, all plates were incubated at $37^{\circ} \mathrm{C}$ for $48 \mathrm{hrs}^{22}$.

\section{Identification of bacterial isolates}

E. coli isolates were identified by API $20 \mathrm{E}$ system (Biomeriux SA, Montalien Vercica and France).

\section{Antimicrobial susceptibility testing by modified Kirby-Bauer disc diffusion $\operatorname{method}^{23}$}

According to the protocol of the infection control lab, the following antibiotics were used (Oxoid, UK): $\beta$-Lactams: Amoxicillin, amoxicillin / clavulanate $(20 / 10 \quad \mu \mathrm{g})$, ceftriaxone $(30 \mu \mathrm{g})$, ceftazidime $(30 \mu \mathrm{g})$, piperacillin / tazobactam $(100 / 10 \quad \mu \mathrm{g})$, cefoperazone / sulbactam $(75 / 30 \mu \mathrm{g})$, cefoperazone $(30 \mu \mathrm{g})$, cefpodoxime $(30 \mu \mathrm{g})$, cefuroxime $(30 \mu \mathrm{g})$, aztreonam $(30 \mu \mathrm{g})$, imipenem $(10 \mu \mathrm{g})$, meropenem $(10 \mu \mathrm{g})$. Aminoglycosides: Amikacin (30 $\mu \mathrm{g})$, gentamicin $(30 \mu \mathrm{g})$. Quinolones: Ciprofloxacin (5 $\mu \mathrm{g})$, levofloxacin $(5 \mu \mathrm{g})$. Others: Nitrofurantoin $(300 \mu \mathrm{g})$, trime-thoprim / sulfamethoxazole $(1.25 / 23.75 \mu \mathrm{g})$.

\section{Detection of extended-spectrum $\beta$ - lactamases}

Selective testing for ESBL production was considered for all $E$. coli isolates.

\section{Screening for ESBL production using Disc Diffusion method ${ }^{24}$}

E. coli isolates were screened for ESBL production using the disc diffusion method proposed by CLSI according to the manufacturer's instructions (Oxoid, UK). This screening method based on measuring the specific zone diameters for the antibiotic discs cefpodoxime (CPD, $10 \mathrm{~g}$ ), ceftazidime (CAZ, $30 \mathrm{~g}$ ), aztreonam (ATM, $30 \mathrm{~g}$ ), ceftriaxone $(\mathrm{CRO}, 30 \mathrm{~g})$ and cefotaxime (CTX, $30 \mathrm{~g})$. CLSI recommends a zone diameter of $\leq 17 \mathrm{~mm}$ for cefpodoxime, $\leq 22 \mathrm{~mm}$ for ceftazidime, $\leq 27 \mathrm{~mm}$ for aztreonam, $\leq 25 \mathrm{~mm}$ for ceftriaxone and $\leq 27 \mathrm{~mm}$ for cefotaxime. When the most of these diameters were measured, this indicated suspected ESBL production; thereafter a phenotypic confirmation test was done to ascertain the diagnosis.

\section{Phenotypic confirmatory tests for ESBL production}

1- Combined disc method or inhibitor potentiated disc diffusion test ${ }^{24}$

Based on the CLSI recommendations, cephalosporin / clavulante combination discs were used to assure the suspected ESBL strains by the combination discs diffusion method. Briefly, the overnight growth in broth of Gramnegative bacteria was adjusted to 0.5 McFarland Standard. The bacterial suspension was spread on Muller Hinton agar (Oxoid, UK) using a sterilized cotton swab. After incubation at room temperature for $15 \mathrm{~min}, 6$ discs (Bioanalyze, Turkey) were put on the plates: Ceftazidime (30 g), ceftazidime / clavulanic acid (30/10 g), cefotaxime $(30 \mathrm{~g})$, cefotaxime / clavulanic acid (30/10 g), cefpodoxime $\left(\begin{array}{ll}10 & \mathrm{~g}\end{array}\right)$ and cefpodoxime / clavulanic acid (10/10 g). An increase in zone size > $5 \mathrm{~mm}$ than zone size when tested alone was accepted as confirmation of ESBL production.

\section{2- Double disc synergy diffusion test (DDST) $)^{25}$}

\section{A- Double disc diffusion test with clavulanic acid}

DDS is a disc diffusion test in which 30 $\mathrm{g}$ antibiotic discs of ceftazidime, ceftriaxone, cefotaxime and aztreonam are placed on the Muller-Hinton agar plate, $25-30 \mathrm{~mm}$ (center to center) from the amoxicillin / clavulanate (20 $\mathrm{g} / 10 \mathrm{~g}$ ) disc. A clear extension of the edge of the antibiotic's inhibition zone toward the disc containing clavulanate is interpreted as synergy, indicating the presence of an ESBL.

\section{B-Double disc diffusion test with piperacillin / tazobactam \\ Some isolates may harbor AmpC- $\beta$ -} lactamases besides ESBLs. In this case clavulanic acid may induce expression of highlevel AmpC production, which may then antagonize rather than protect the antibacterial activity of the partner $\beta$-lactam ${ }^{26}$, thus the presence of an ESBL can be masked by the expression of an AmpC-type enzyme in the strain (by masking any synergy with ESBL). 
Thus, when testing for ESBL production in these isolates, much better inhibition is achieved with the sulfones, such as tazobactam, which are therefore, preferable inhibitors for ESBL detection tests with these organisms.

\section{3- ESBL-E-test}

The ESBL-E-Test strips were obtained from (AB biodisc, Solna, Sweden) ceftazidime / ceftazidime + clavulanic acid (TZ/TZL) and cefotaxime and cefotaxime + clavulanic acid (CT/CTL) in accordance with the manufacturer's instructions. One end of each strip contains a gradient concentration of either ceftazidime (TZ) (MIC range 0.5 to $32 \mathrm{~g} / \mathrm{ml}$ ) or cefotaxime (CT) (MIC range of $0.25 \mu \mathrm{g}$ to $16 \mu \mathrm{g})$. The other end of the strip with a gradient of ceftazidime plus a constant concentration of clavulanate TZ/TZL (0.064-4 $\mathrm{g} / \mathrm{ml}$ plus $4 \mathrm{~g} / \mathrm{ml}$ of clavulanic acid) or with a gradient of cefotaxime plus a constant concentration of clavulanate CT/CTL $(0.25 \mu \mathrm{g}$ $16 \mu \mathrm{g}$ plus $4 \mu \mathrm{g}$ of clavulanic acid ${ }^{27}$. After overnight growth, the organism was emulsified in saline solution to a turbidity of 0.5 McFarland standard. The suspension was spread on a Muller Hinton agar plate with a cotton swab. After the plates were dried for 15 min, the E-Test strips were placed on them, after incubation at $35^{\circ} \mathrm{C}$ for $18 \mathrm{hrs}$. The MIC was interpreted as the point of intersection of the inhibition ellipse with the edge of the test strip. The results were interpreted as ESBL positive if the MIC ratio for TZ/TZL was $\geq 8$.

\section{Determination of the genetic type of $\beta$ - lactamase by polymerase chain reaction (PCR)}

All phenotypically confirmed ESBL producing strains were investigated to determine the probable type of $\beta$-lactamase enzyme which was responsible for resistance.
Extraction of DNA was performed using DNA extraction kit (Jena Bioscience, Germany) Cat. No. pp. 206s. PCR amplification of bla genes, including $b l a_{\mathrm{TEM}}, b l a_{\mathrm{SHV}}$ and $b l a_{\mathrm{CTX}-\mathrm{M}}$ was performed with $T a q$ master mix DNA polymerase (Jena Bioscience, Germany) using primers listed in table 1, under the following conditions:

a- Initial denaturation step: $94^{\circ} \mathrm{C}$ for $5 \mathrm{~min}$.

b- 30 cycles consisting of:

Denaturation: $94^{\circ} \mathrm{C}$ for $1 \mathrm{~min}$.

Annealing: $61^{\circ} \mathrm{C}$ for $1 \mathrm{~min}$.

DNA extension: $72^{\circ} \mathrm{C}$ for $1 \mathrm{~min}$.

c- Final extension: $72^{\circ} \mathrm{C}$ for $5 \mathrm{~min}$.

Further analysis of the CTX-M enzymes using specific primers listed in table 2 was done to determine the specific group of CTX$\mathrm{M}$ (1, 2, 8 and 9) under the same conditions. All PCR amplicons were verified by gel electrophoresis on a $2 \%$ agarose gel electrophoresis (Biometra-Agaorese gel mini, Germany), stained with Ethidium bromide $(1 \mu \mathrm{l} / \mathrm{ml})$ for $30 \mathrm{~min}$ under $100 \mathrm{~V}$ in $1 \mathrm{X} \mathrm{TAE}$ buffer and visualized by ultraviolet transilluminator HeroLab UVT-20M, Germany). PCR amplicon sizes were calculated by a comparison with $100 \mathrm{bp}$ molecular weight DNA ladder (Jena Bioscience, Germany).

\section{RESULTS AND DISCUSSION}

\section{Results}

Out of the 700 urine samples collected from patients suspected to have UTI, a total of 340 were culture positive. The rate of UTI was $40 \%(140 / 350)$ for community patients and $57.1 \%(200 / 350)$ for hospitalized patients. The urinary isolates source whether community or hospital is shown in table 3.

Table 1: Multiplex PCR primers for detection of $b l a_{T E M}, b l a_{S H V}$ and $b l a_{C T X}$.

\begin{tabular}{|l|l|c|c|c|}
\hline \multicolumn{1}{|c|}{ Gene } & \multicolumn{1}{|c|}{ Sequence of primers } & Size bp & $\begin{array}{c}\text { Annealing } \\
\text { Temperature }\left({ }^{\circ} \mathrm{C}\right)\end{array}$ & References \\
\hline SHV-F & 5'GATGAACGCTTTCCCATGATG3' & 214 & 59 & $(28)$ \\
SHV-R & 5'CGCTGTTATCGCTCATGGTAA3' & & & \\
\hline TEM-F & 5'AGTGCTGCCATAACCATGAGTG3' & 550 & 63 & $(28)$ \\
TEM-R & 5'CTGACTCCCCGTCGTGTAGATG3' & & & \\
\hline CTX UNIV-F & 5'TCTTCCAGAATAAGGAATCCC3' & 909 & 57 & $(29)$ \\
CTX UNIV-R & 5'CCGTTTCCGCTATTACAAAC3' & & & \\
\hline
\end{tabular}

$\mathrm{F}=$ Forward primer, $\mathrm{R}=$ Reverse primer 
Table 2: Multiplex PCR primers for detection of $\operatorname{bla}_{C T X(1,2,8 \text { and } 9) \text {. }}$

\begin{tabular}{|c|c|c|c|c|}
\hline Gene & Sequence of primers & Size bp & $\begin{array}{c}\text { Annealing } \\
\text { Temperature }\left({ }^{\circ} \mathrm{C}\right)\end{array}$ & References \\
\hline $\begin{array}{l}\text { CTX-1-F } \\
\text { CTX-1-R }\end{array}$ & $\begin{array}{l}\text { 5'GGACGTACAGCAAAAACTTGC3' } \\
\text { 5'CGGTTCGCTTCACTTTTCTT3' }\end{array}$ & 891 & 59 & (28) \\
\hline $\begin{array}{l}\text { CTX-2-F } \\
\text { CTX-2-R }\end{array}$ & $\begin{array}{l}\text { 5'CGGTGCTTAAACAGAGCGAG3' } \\
\text { 5'CCATGAATAAGCAGCTGATTGCCC3' }\end{array}$ & 624 & 60 & (30) \\
\hline $\begin{array}{l}\text { CTX-8-F } \\
\text { CTX-8-R }\end{array}$ & $\begin{array}{l}\text { 5'ACGCTCAACACCGCGATC3' } \\
\text { 5'CGTGGGTTCTCGGGGATAA3' }\end{array}$ & 490 & 58 & (30) \\
\hline $\begin{array}{l}\text { CTX-9-F } \\
\text { CTX-9-R }\end{array}$ & $\begin{array}{l}\text { 5'GATTGACCGTATTGGGAGTTT3' } \\
\text { 5'CGGCTGGGTAAAATAGGTCA3' }\end{array}$ & 947 & 58 & (30) \\
\hline
\end{tabular}

$\mathrm{F}=$ Forward primer, $\mathrm{R}=$ Reverse primer

Table 3: Distribution of urinary isolates according to their infection onset whether community or hospital-acquired.

\begin{tabular}{|l|c|c|}
\hline \multicolumn{1}{|c|}{$\begin{array}{c}\text { Isolates } \\
(\mathrm{n}=340)\end{array}$} & $\begin{array}{c}\text { Community-acquired } \\
(\mathrm{n}=134)\end{array}$ & $\begin{array}{c}\text { Hospital-acquired } \\
(\mathrm{n}=200)\end{array}$ \\
\hline E. coli $(\mathrm{n}=136)$ & $76(54.28 \%)$ & $60(30 \%)$ \\
\hline K. pneumoniae $(\mathrm{n}=143)$ & $41(29.28 \%)$ & $102(51 \%)$ \\
\hline S. aureus $(\mathrm{n}=18)$ & $10(7.14 \%)$ & $8(4 \%)$ \\
\hline Ps. aeruginosae $(\mathrm{n}=24)$ & $2(1.42 \%)$ & $22(11 \%)$ \\
\hline Coagulase-negative Staph. $(\mathrm{n}=17)$ & $5(3.57 \%)$ & $6(3 \%)$ \\
\hline Candida spp. $(\mathrm{n}=8)$ & $6(4.28 \%)$ & $2(1 \%)$ \\
\hline
\end{tabular}

\section{Antimicrobial susceptibility testing}

Antibiotics sensitivity of $E$. coli isolates showed that the isolated organisms were $(100 \%)$ sensitive to meropenem, $(75.73 \%)$ to piperacillin / tazobactam while, $(62.5 \%)$ to cefoperazone / sulbactam, (57.35\%) to levofloxacin, $(54.41 \%)$ to nitrofurantoin and gentamicin $(52.20 \%)$.

\section{Analysis of ESBL production}

Preliminary screening tests showed that $76.47 \%(104 / 136)$ of isolates were considered as potential producers of ESBLs. Confirmatory tests (Combined Disc method, Double-Disc Synergy "DDS" Tests, and ESBL-E-Test) were carried out to confirm the production of ESBL (Figs. 1, 2, 3 and 4). Considering confirmatory, a total of $52.94 \%(72 / 136)$ of isolates were confirmed by ESBL-E-Test to be ESBL producers as the ESBL-E-Test is the golden standard phenotypic method for ESBL detection. While, DDS with tazobactam revealed 3 additional isolates to be ESBLs producers (Table 4).
Determination of the genotype of $\beta$ lactamase by PCR

All positively screened $E$. coli isolates (104) were analyzed by PCR. A total of 74/104 $(71.15 \%)$ of $E$. coli isolates were confirmed to be ESBL producers. Our aim was to determine the probable type of $\beta$-lactamase gene which is responsible for resistance. It was found that CTX-M (909 bp) was the main type of $\beta$ lactamase (42.3\%). TEM (431 bp) was second (13.46\%), SHV (214 bp) (3.84\%) was third. Some strains produced more than one type of $\beta$-lactamase. Eight strains produced both enzymes TEM and CTX-M (7.69\%); one strain produced TEM and SHV enzymes $(0.96 \%)$ and three strains produced TEM, SHV and CTXM-1 enzymes (2.88\%) as shown in table 5 and figure 5 .

Further analysis of CTX-M positive isolates was done to determine the groups of CTX-M enzymes and revealed that CTX-Mgroup1 (891 bp) was the main group (81.81\%), CTX-M-group 9 (947 bp) was second (9.09\%), CTX-M-group 2 (624 bp) was third while no isolate produced CTX-M-group 8 (Table 6 and Fig. 6). 


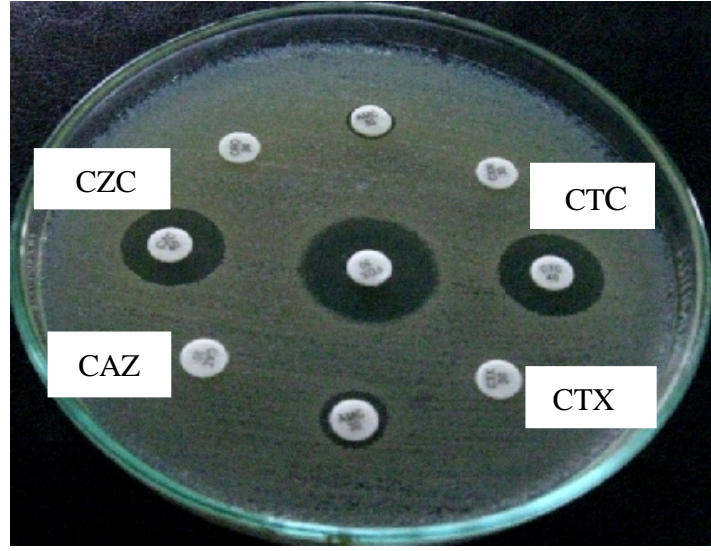

Fig. 1: Combined disc method.

(CAZ) ceftazidime, (CZC) ceftazidime plus clavulanic acid, cefotaxime (CTX) and (CTC) cefotaxime plus clavulanic acid.

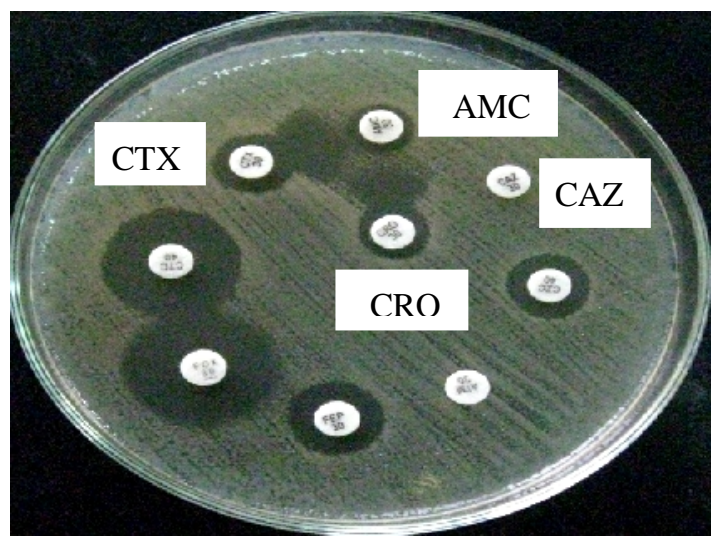

Fig. 2: Double disc synergy test (DDS).

(AMC) Amoxicillin/clavulanic acid, (CAZ) ceftazidime, (CRO) ceftriaxone and (CTX) cefotaxime.

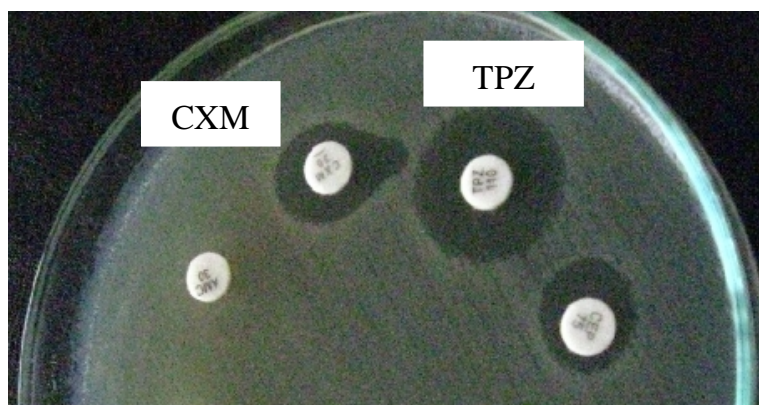

Fig. 3: Double disk synergy test (DDS) with tazobactam

(CXM) cefuroxime, (TPZ) piperacillin / tazobactam.

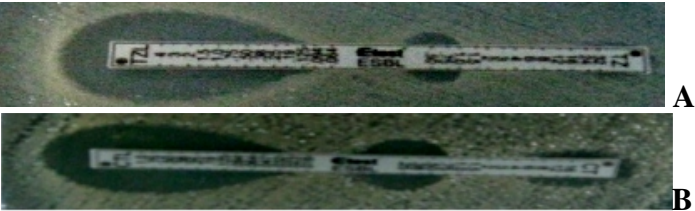

Fig. 4: ESBL-E-Test.

A) Ceftazidime (TZ) plus ceftazidime / clavulanic acid (TZL) positive isolate.

B) Cefotaxime (CT) plus cefotaxime / clavulanic acid (CTL) positive isolate.

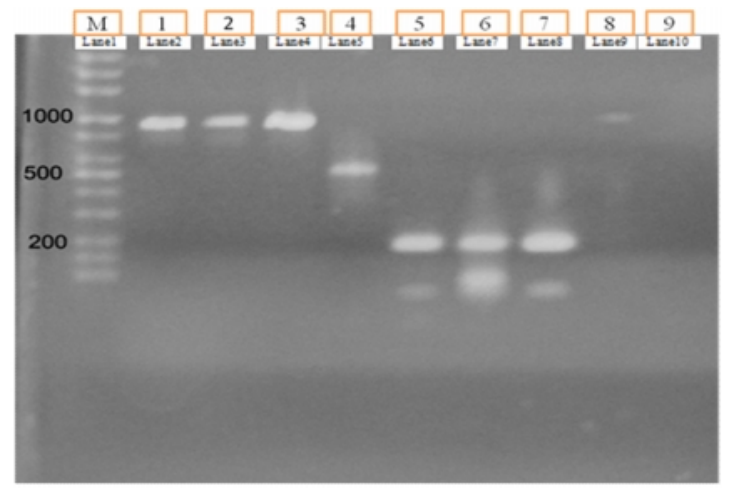

Fig. 5: Agarose gel electrophoresis of amplified bla $a_{T E M}$, SHV and CTX-M DNA.

Lane (1) M: DNA marker $100 \mathrm{bp}$.

Lane (3, 4, and 9): CTX-M gene (909 bp).

Lane (5): TEM gene (550 bp)

Lane (6,7 and 8): SHV gene (214 bp).

Lane (2): Positive control.

Lane (10): Negative control.

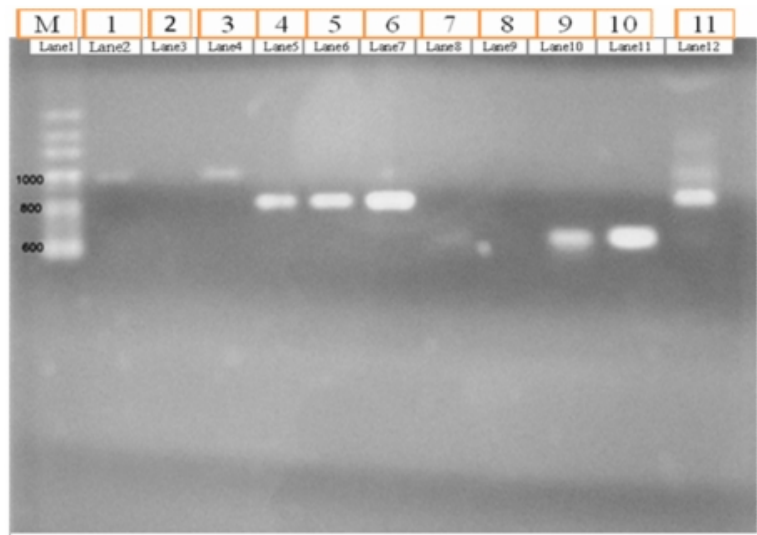

Fig. 6: Agarose gel electrophoresis of amplified DNA of bla ${ }_{\text {CTX-M }}$ groups.

Lane (1) M: DNA marker $100 \mathrm{bp}$.

Lane (2, 4, and 12): CTX-M group-9 gene (947bp).

Lane (5, 6, and 7): CTX-M group-1 gene (891bp).

Lane (10 and 11): CTX-M group-2 gene (624bp). 
Table 4: Phenotypic methods for detection of ESBLs among E. coli isolates.

\begin{tabular}{|c|c|c|c|c|c|}
\hline \multirow[b]{2}{*}{ Organism tested } & \multirow{2}{*}{$\begin{array}{l}\text { Screening } \\
\text { test }\end{array}$} & \multicolumn{4}{|c|}{ Confirmatory tests } \\
\hline & & $\begin{array}{c}\text { DDS with } \\
\text { clavulanic acid }\end{array}$ & $\begin{array}{l}\text { DDS with } \\
\text { tazobactam }\end{array}$ & $\begin{array}{c}\text { Combined disc } \\
\text { method }\end{array}$ & ESBL-E-Test \\
\hline E. coli $=76$ (community) & $53(69.73 \%)$ & $30(39.47 \%)$ & $30(39.47 \%)$ & $29(38.15 \%)$ & $30(39.47 \%)$ \\
\hline E. coli $=60$ (nosocomial) & $51(85 \%)$ & $42(70 \%)$ & $45(75 \%)$ & $42(70 \%)$ & $42(70 \%)$ \\
\hline Total number $=136$ & $104(76.47 \%)$ & $72(52.94 \%)$ & $75(55.14 \%)$ & $71(52.20 \%)$ & $72(52.94 \%)$ \\
\hline
\end{tabular}

Table 5: Genotyping of ESBLs producing E. coli.

\begin{tabular}{||l|c|c|c||}
\hline \multicolumn{1}{|c|}{ Genetic type } & $\begin{array}{c}\text { Community acquired } \\
\text { E. coli }(\mathrm{n}=53)\end{array}$ & $\begin{array}{c}\text { Nosocomial } \\
\text { E. coli }(\mathrm{n}=51)\end{array}$ & $\begin{array}{c}\text { Total percentage } \\
(\mathrm{n}=104)\end{array}$ \\
\hline TEM & $8(15.09 \%)$ & $6(11.76 \%)$ & $14(13.46 \%)$ \\
\hline SHV & $2(3.77 \%)$ & $2(3.92 \%)$ & $4(3.84 \%)$ \\
\hline CTX-M & $12(22.64 \%)$ & $32(62.74 \%)$ & $44(42.03 \%)$ \\
\hline TEM+SHV & $1(1.88 \%)$ & ----------- & $1(0.96 \%)$ \\
\hline TEM+CTX-M & $4(7.54 \%)$ & $4(7.84 \%)$ & $8(7.69 \%)$ \\
\hline TEM+SHV+CTX-M & $3(5.66 \%)$ & --------- & $3(2.88 \%)$ \\
\hline Total percentage & $30(56.60 \%)$ & $44(86.27 \%)$ & $74(71.15 \%)$ \\
\hline
\end{tabular}

Table 6: Subgenotypes of CTX-M genes among E. coli.

\begin{tabular}{||c|c|c|c||}
\hline \hline Genetic type & $\begin{array}{c}\text { Community acquired } \\
\text { E. coli }(\mathrm{n}=12)\end{array}$ & $\begin{array}{c}\text { Nosocomial } \\
\text { E. coli }(\mathrm{n}=32)\end{array}$ & $\begin{array}{c}\text { Total } \\
(\mathrm{n}=44)\end{array}$ \\
\hline CTX-M-group 1 & $10(83.33 \%)$ & $26(81.25 \%)$ & $36(81.81 \%)$ \\
\hline CTX-M- group 2 & ------ & $2(6.25 \%)$ & $2(4.54 \%)$ \\
\hline CTX-M- group 8 & ------ & ----- & ------ \\
\hline CTX-M- group 9 & $2(16.66 \%)$ & $2(6.25 \%)$ & $4(9.09 \%)$ \\
\hline
\end{tabular}

\section{Discussion}

Urinary tract infections (UTIs) are amongst the most common infections, with an estimated annual global incidence of at least 250 million cases, and are costly to both patients and healthcare funding systems ${ }^{31}$.This study showed that the rate of community acquired UTI (CA-UTI) was $40 \%$, comparable to those reported by Oladipo et al. ${ }^{32}$ in Nigeria where the rate was $35.8 \%$. While the rate of nosocomial UTI in this study was $57.14 \%$, which was higher than that reported by Tirthankar et al..$^{33}$ in India where a rate of $45 \%$ was reported.

The leading pathogens (CA-UTI) were $E$. coli $54.28 \%$ and $K$. pneumoniae $29.28 \%$. Our results are consistent with the results of North American Urinary Tract Infection Collaborative Alliance (NAUTICA) ${ }^{34}$, which revealed that the common pathogen causing community acquired UTI is E. coli $57.5 \%$ followed by $K$. pneumoniae $23.5 \%$. While the leading pathogen causing nosocomial UTI were $K$. pneumoniae $(51 \%)$ which, outnumbered $E$. coli $(30 \%)$ for overall prevalence of nosocomial UTI. Our result closely mirrors what was observed by Taher and $\mathrm{Ali}^{35}$ in Iran where the rate for $K$. pneumoniae $46 \%$ and $E$. coli $25 \%$, and also similar to Mirsalehian et $a l .{ }^{36}$ who reported that the rate of nosocomial UTI caused by $K$. pneumoniae was $36.66 \%$ $(22 / 60)$ which was higher than those caused by E. coli $20 \%$ (12/60). Also, Ahmed et al. ${ }^{37}$ reported that $K$. pneumoniae was the most common isolate $28 / 175(10.3 \%$ ) followed by $E$. coli $(8.6 \%)$ among nosocomial blood stream infections in intensive care units at Assiut University Hospitals.

ESBLs continue to be a major problem in clinical setups the world over, conferring resistance to expanded spectrum cephalosporin. ESBL isolates are prevalent in developing countries and multiple resistant to gentamicin, ciprofloxacin, tetracycline, sulphamethaxazole I trimethoprime. They are inhibited by clavulanate (CA), sulbactam, or tazobactam. This poses a challenge to treatment of patients infected with ESBL isolates. Knowledge about their prevalence is essential to guide towards appropriate antibiotic treatment ${ }^{38}$. 
Besides, the routine detection of ESBL isolates and proper control measures are urgently needed for appropriate management ${ }^{39 \& 10}$.

Considering confirmatory tests a total of $30(39.47 \%)$ of community isolates and 42 (70\%) of nosocomial isolates were confirmed to be ESBL producers by ESBL-E-Test. Analysis of the community and nosocomial isolates showed that similar results were obtained by the Combined Disc method, the Double Disc Synergy "DDS" test with clavulanic acid, with 71 isolates being found to be ESBL producers. The double disc synergy test using tazobactam revealed an additional 3 strains that were positive for ESBL. This suggests that those 3 strains produce an ESBL enzyme and AmpC-enzyme. With these organisms, Clavulanic acid may induce expression of high-level AmpC production and may then antagonize rather than protect the antibacterial activity of the partner $\beta$-lactam ${ }^{26}$. Thus, the presence of an ESBL can be masked by the expression of an AmpC-type enzyme in the same strain (by masking any synergy with ESBLs) ${ }^{40}$. As a result, when testing for ESBL production in these organisms, we should consider using sulfones such as tazobactam and sulbactam as $\beta$-lactamase inhibitors ${ }^{41}$. Although the exact reasons are not completely understood, the pressure to use non- $\beta$-lactam antibiotics may be responsible for the coexistence of ESBL and AmpC. The genes coding for ESBLs and other non- $\beta$-lactam resistance genes (e.g. aminoglycosides or Cotrimoxazole) often reside within the same conjugative plasmid and therefore are transmitted together from one strain to anotherand can be co-selected under the pressure of prior multidrug usage ${ }^{42}$.

In our study, the percentage ESBL producing E. coli was $52.94 \%$ (72/136). The prevalence and relative distribution of ESBLs vary depending on the facility and the level of care taken to control nosocomial UTI. These factors also vary with geographic location and time $^{43}$.

In the present study, the prevalence of ESBL producing $E$. coli community isolates was $(39.47 \%)$. Our results are comparable to those obtained by Chayakulkeeree et al. ${ }^{44}$ who reported that the rate of ESBL producing $E$. coli was $33.3 \%$. The difference between the two studies may be of the geographical difference, the number of the studied population and time difference. On the other hand a higher level of extended-spectrum $\beta$ lactamases was reported among nosocomial isolates where the rate was $(70 \%)$. A recent study in Egypt reported by Ahmed et al. ${ }^{37}$ revealed an increased level of ESBL production among nosocomial blood stream infections in intensive care units at Assiut University Hospitals where the rate was $64.7 \%$. Another report from Egypt indicating a relatively increased level of ESBL- producing E. coli urinary isolates $(60.9 \%)$ was reported by Al-Agamy et $a l .{ }^{45}$ who confirmed the high rate of ESBLs in Egypt. The difference with our study may be assumed to the difference in the study number population, time of collection, types of organisms tested and tests done for ESBLs confirmation.

During this study, the type of ESBL gene was determined by polymerase chain reaction (Table 5) which showed that CTX-M was the main type of $\beta$-lactamases, followed by TEM, then SHV. Some strains produced more than one type of $\beta$-lactamase; (TEM + SHV) were produced by one isolate, (TEM + CTX-M) by 8 isolates and 3 strains produced (TEM + SHV + CTX-M) enzymes. In Egypt, similar results were reported by Fam et al. ${ }^{46}$ who observed that the majority of E. coli ESBL producers $(75 \%)$ were isolated from urine, and the common ESBL type was CTX-M-15 (CTX-M group-1). The high rate of CTX-M in this study was confirmed by Heffernan et al. ${ }^{47}$ where the rate was $97.6 \%$ among $E$. coli and $K$. pneumoniae urinary isolates.

Further analysis of CTX-M positive isolates was done to determine the groups of CTX-M enzymes and the results showed that CTX-M-group1 was the main group, CTX-Mgroup 9 was second, CTX-M- group 2 was third and negative CTX-M- group8 as shown in table 6.

In accordance with our results Mendonca et $a l .^{48}$ reported that the majority of the urine isolates had CTX-M enzymes of group-1, [CTX-M-15 91.95\%] (109/119) and 9 strains (7.56\%) had CTX-M enzymes of group-9 CTX-M-14. A lower result was reported by Tofteland et al. ${ }^{49}$ who reported that sequence grouping and typing of CTX-M enzymes revealed that the CTX-M-1 group was the most 
prevalent with a rate of $64.44 \%$ (29/45), followed by CTX-M-9 group $33.33 \%$ (15/45).

\section{Conclusion}

In conclusion, it is very important for the clinical microbiology laboratories to have the ability to detect and report ESBLs production in clinical isolates of Gram-negative bacteria. Besides, monitoring and judicious usage of extended-spectrum cephalosporin, periodic surveillance of antibiotic resistance patterns and efforts to decrease empirical antibiotic therapy would go a long way in addressing some of the problems associated with ESBL. Carbapenems are the most active and reliable treatment options for infections caused by ESBL isolates, however, overuse of carbapenems may lead to resistance of other Gram-negative organisms.

\section{REFERENCES}

1- A. Ronald, "The etiology of urinary tract infection traditional and emerging pathogens", Am. J. Med., 113 (supp 11A), 14S-19S (Level III) (2002).

2- W. E. Stamm and S. R. Norrby, "Urinary tract infections: disease panorama and challenges", J. Infect. Dis., 183, pp. s1-s4 (2001).

3- M. D. Bethesda, "National kidney and urologic diseases information clearing house", NIH Publication, No. 08, 3925 (2005).

4- D. C. Bean, K. Daniel and W. W. David, "Antimicrobial resistance in community and nosocomial $E$. coli urinary tract isolates, London 2005-2006", Annals of Clin. Microbiol. Antimicrob., 25, 7-13 (2008).

5- T. Hooton, "The current management strategies for community-acquired urinary tract infection", Infect. Dis. Clin. North. Am., 17, 303-332 (2003).

6- A. A. Kader and K. Angamuthu, "Extended-spectrum $\beta$-lactamases in urinary isolates of E. coli, K. pneumoniae and other Gram-negative bacteria in a hospital in Eastern Province, Saudi Arabia", Saudi Med. J., 26 (6), 956-959 (2005).

7- A. Valverde, T. M. Coque, Garcia- M. L. San, F. Baquero and R. Canton, "Complex molecular epidemiology of extendedspectrum $\beta$-lactamases in $K$. pneumoniae: a long-term perspective from a single institution in Madrid", J. Antimicrob. Chemother., 61, 64-72 (2008).

8- J. D. Pitout, M. D. Reisbig and E. C. Venter, "Modification of the double-disc test for detection of Enterobacteriaceae producing extended-spectrum and $\mathrm{AmpC}$ $\beta$-lactamases", J. Clin. Microbiol., 41 (8), 3933-3935 (2003).

9- M. J. Schwaber, P. M. Raney and J. K. Rasheed, "Utility of NCCLS guidelines for identifying extended-spectrum $\beta$ lactamases in non-E. coli and nonKlebsiella spp. of Enterobacteriaceae", ibid., 42 (1), 294-298 (2004).

10- S. M. Drawz and R. A. Bonomo, "Three decades of $\beta$-lactamase inhibitors", Clin. Microbiol. Rev., 3 (1), 160-201 (2010).

11- C. H. Lee, L. H. Su, Y. F. Tang and J. W. Liu, "Treatment of ESBL-producing $K$. pneumoniae bacteraemia with carbapenems or flomoxef: A retrospective study and laboratory analysis of the isolates", J. Antimicrob. Chemother., 58 (5), 10741077 (2006).

12- A. D. Harris, J. C. McGregor, J. A. Johnson, S. M. Strauss, A. C. Moore, H. C. Standiford, J. N. Hebden and J. G. Jr. Morris, "Risk factors for colonization with extended-spectrum $\beta$-lactamase-producing bacteria and intensive care unit admission", Emerg. Infect. Dis., 13 (8), 1144-1149 (2007).

13- E. T. Lautenbach, J. B. Patel, W. B. Bilker, P. H. Edelstein and N. O. Fishman, "Extended-spectrum $\beta$-lactamase-Producing $E$. coli and $K$. pneumoniae: Risk factors for infection and impact of resistance on outcomes", Clin. Infect. Dis., 32, 1162-1171 (2001).

14- K. S. Thomson, "Controversies about extended-spectrum and AmpC $\beta$ lactamases", Emerg. Infect. Dis., 7 (2), 333-336 (2001).

15- D. L. Paterson, "Resistance in Gramnegative bacteria: Enterobacteriaceae", Am. J. Med., 119 (6SUPPL. 1), S20-S28 (2006).

16- National Nosocomial Infections Surveillance (NNIS) System Report, data summary from January 1992 through June 
2004, Issued October. Am. J. I. C., 32 (8), 470-485 (2004).

17- D. L. Paterson, W. C. Ko and A. Von Gottberg, "Antibiotic therapy for $K$. pneumoniae bacteremia: implications of production of extended-spectrum $\beta$ lactamases", Clin. Infect. Dis., 39, 31-7 (2004).

18- Clinical and Laboratory Standards Institute (CLSI), "Performance Standards for Antimicrobial Susceptibility Testing", $17^{\text {th }}$ Informational Supplement M100-S17. Vol. 27, Clinical and Laboratory Standards Institute, Wayne, PA. (2007).

19- G. B. Schumann and F. N. Greenberg, "Usefulness of macroscopic urine analysis as a screening procedure", Am. J. Clin. Pathol., 71, 452-6 (1979).

20- P. D. Hoeprich, "Culture of the urine", J. Lab. Clin. Med., 56, 899-907 (1960).

21- M. Cheesbrough, "Medical Microbiology for Tropical Countries", Vol. II. "Microbiology", $1^{\text {st }}$ ELBS ed. Cambridge, UK, 1989, pp. 248-263.

22- M. Cheesbrough, "District Laboratory Practice in Tropical Countries", Cambridge University Press, UK, Part II, 2006, p. 63.

23- E. W. Koneman, S. D. Allen, W. M. Janda, P. C. Schreckenberger, W. C. Winn and editors, "The Enterobacteriaceae", In: "Color Atlas \& Textbook of Diagnostic Microbiology", $5^{\text {th }}$ ed. Philadelphia: JB Lippincott Co., 1997, pp. 171-230.

24- Clinical and Laboratory Standards Institute (CLSI), "Performance Standards for Antimicrobial Susceptibility Testing", $17^{\text {th }}$ Informational Supplement M100S17., Vol. 27. Clinical and Laboratory Standards Institute, Wayne, PA. (2005).

25- V. Jarlier, M. H. Nicolas, G. Fournier and A. Philippon, "Extended-spectrum $\beta$ lactamases conferring transferable resistance to newer $\beta$-lactam agents in Enterobacteriaceae hospital prevalence and susceptibility patterns", Rev. Infect. Dis., 10, 867-878. (1988).

26- P. D. Lister, V. M. Gardner and C. C. Sanders, "Clavulanate induces expression of the Ps. aeruginosa AmpC cephalosporinase at physiologically relevant concentrations and antagonizes the antibacterial activity of ticarcillin", Antimicrob. Agents Chemother., 43, 882-889 (1999).

27- M. G. Cormican, S. A. Marshall and R. N. Jones, "Detection of extended-spectrum $\beta$ lactamase (ESBLs)-producing strains by the ESBL- E-Test screen", J. Clin. Microbiol., 34 (8), 1880-1884 (1996).

28- J. Kim, J. Semi, R. Hogeun, L. Bokkwon, P. Misun, L. Hoanjong, M. D. Jina and K. Seonghan, "Rapid detection of extendedspectrum $\beta$-lactamase (ESBL) for Enterobacteriaceae by use of a multiplex PCR-based method", Infect. Chemother., 41 (3), 181-184 (2009).

29- E. Stürenburg, A. Kuhn, D. Mack and R. Laufs, "A novel extended-spectrum $\beta$ lactamase CTX-M-23 with a P167T substitution in the active site omega loop associated with ceftazidime resistance", J. Antimicrob. Chemother., 54, 406-409 (2004).

30- N. H. Ryoo, E. C. Kim, S. G. Hong, Y. J. Park, K. Lee, I. K. Bae, E. H. Song and S. H. Jeong, "Dissemination of SHV-12 and CTX-M-type extended-spectrum $\beta$ lactamases among clinical isolates of $E$. coli and $K$. pneumoniae and emergence of GES-3 in Korea", ibid., 56, 698-702 (2005).

31- A. R. Ronald, L. E. Nicolle, E. Stamm, J. Krieger, J. Warren and A. Shaeffer, "Urinary tract infection in adults: research priorities and strategies", Int. J. Antimicrob. Agents, 17, 343-8 (2001).

32- A. A. Oladipo, A. Abdul-Rasheed, W. Babatunde Odetoyin, and L. Adebayo, "Antimicrobial resistance in E. coli strains from urinary tract infections", J. Nat. Med. Assoc., 101, 1268-1273 (2009).

33- M. Tirthankar, K. Pramod, S. Gita and Y. R. Medha, "Nosocomial infections in geriatric patients admitted in ICU", J. I. A. G., 2, 61-64 (2005).

34- G. G. Zhanel, T. L. Hisanaga, N. M. Laing, M. R. DeCorby, K. A. Nichol, B. Weshnoweski, J. Johnson, A. Noreddin D. E. Low, J. A. Karlowsky; for the NAUTICA Group and D. J. Hoban, "Antibiotic resistance in outpatient urinary isolates: final results from the North American Urinary Tract Infection Collaborative Alliance (NAUTICA)", Int. J. Antimicrob. Agents, 26, 380-388 (2005). 
35- M. T. Taher and G. Ali, "Symptomatic nosocomial urinary tract infection in ICU patients: identification of antimicrobial resistance pattern", IJCID, 4 (1), 25-29 (2009).

36- A. Mirsalehian, F. Akbari-Nakhjavani, A. Peymani, B. Kazemi, F. J. Ameli and S. M. Mirafshar, "Prevalence of extendedspectrum $\beta$-lactamase-producing enterobacteriaceae by phenotypic and genotypic methods in intensive care units in Tehran, Iran", DARU, 16, (3), 169-173 (2008).

37- S. H. Ahmed, E. A. Daef, M. S. Badary, M. A. Mahmoud and A. A. Abd-Elsayed, "Nosocomial blood stream infection in intensive care units at Assiut University Hospitals (Upper Egypt) with special reference to extended-spectrum $\beta$ lactamase producing organisms", BMC Research Notes, 2 (76), 1-11 (2009).

38- P. Agrawal, A. Ghosh and S. Kumar, "Prevalence of extended-spectrum $\beta$ lactamases among $E$. coli and $K$. pneumoniae isolates in a tertiary care hospital", Indian J. Pathol. Microbiol., 51 (1), 139-142 (2008).

39- S. E. Mshana, "State of the globe: Evaluating the existence of extendedspectrum $\beta$-lactamases", J. Global Infect. Dis., 1 (2), 85-86 (2009).

40- P. A. Bradford, C. Urban, N. Mariano, S. J. Projan, J. J. Rahal and K. Bush, "Imipenem resistance in K. pneumoniae is associated with the combination of ACT1, a plasmid-mediated AmpC $\beta$-lactamase and the loss of an outer membrane protein", Antimicrob. Agents Chemother., 41, 563-569 (1997).

41- K. S. Thomson, C. C. Sanders and E. S. Moland, "Use of microdilution panels with and without $\beta$-lactamase inhibitors as a phenotypic test for $\beta$-lactamase production among E. coli, Klebsiella spp., Enterobacter spp., Citrobacter freundii and Serratia marcescens", ibid., 43, 13931400 (1999).

42- C. Mabilat and P. Courvalin, "Development of "oligotyping" for characterization and molecular epidemiology of TEM $\beta$-lactamases in members of the family Entero-bacteriaceae", ibid., 34, 2210-2216 (1990).
43- M. Shah, A. Malik, M. Agrawal and S. Singhal, "Phenotypic detection of extended-spectrum and AmpC $\beta$ lactamases by a new spot-inoculation method and modified three-dimensional extract test: comparison with the conventional three-dimensional extract test", J. Antimicrob. Chemother., 54, 684687 (2004).

44- M. Chayakulkeeree, P. Junsriwong, A. Keerasuntonpong, C. Tribuddharat and V. Thamlikitkul, "Epidemiology of extendedspectrum $\beta$-lactamase producing Gramnegative bacilli at Siriraj hospital, Thailand", J. Clin. Microbiol., 36 (6), 1503-1509 (2005).

45- M. H. M. Al-Agamy, M. S-E. M. Ashour and I. Wiegand, "First description of CTX-M $\beta$-lactamase-producing clinical $E$. coli isolates from Egypt", Int. J. Antimicrob. Agents, 27 (6), 545-548 (2006).

46- N. S. Fam, L. Véronique, F. Salwa, A. Laila, M. Estelle, D. Doaa, E. Inas, A. Aisha, K. John and N. Marie-Hélène, "CTX-M-15-producing E. coli clinical isolates in Cairo (Egypt), including isolates of clonal complex ST10 and clones ST131, ST73, and ST405 in both community and hospital settings", Microbial Drug Resistance, 17 (1), 67-73 (2011).

47- H. M. Heffernan, R. E. Woodhouse, C. E. Pope and T. K. Blackmore, "Prevalence and types of "extended-spectrum $\beta$ lactamases among urinary E. coli and Klebsiella spp. in New Zealand", Int. J. Antimicrob. Agents, 34, 544-549 (2009).

48- N. Mendonca, J. Leitao, V. Manageiro, E. Ferreira and M. Canica, "Spread of extended-spectrum $\beta$-lactamase CTX-Mproducing $E$. coli clinical isolates in community and nosocomial environments in Portugal", Antimicrob. Agents Chemother., 51 (6), 1946-55 (2007).

49- S. Tofteland, B. Haldorsen, K. H. Dahl, G. S. Simonsen, M. Steinbakk and T. R. Walsh, "Effects of phenotype and genotype on methods for detection of extended spectrum- $\beta$-lactamase-producing clinical isolates of E. coli and K. pneumoniae in Norway", J. Clin. Microbiol., 45 (1), 199205. (2007). 